\title{
Diet, nutrition and the prevention of cancer
}

\author{
Timothy J Key ${ }^{1, *}$, Arthur Schatzkin ${ }^{2}$, Walter C Willett ${ }^{3}$, Naomi E Allen ${ }^{1}$, \\ Elizabeth A Spencer ${ }^{1}$ and Ruth C Travis ${ }^{1}$ \\ ${ }^{1}$ Cancer Research UK Epidemiology Unit, University of Oxford, Oxford, UK: ${ }^{2}$ Nutritional Epidemiology Branch, \\ Division of Cancer, Epidemiology and Genetics, National Cancer Institute, Bethesda, USA: ${ }^{3}$ Departments of \\ Epidemiology and Nutrition, Harvard School of Public Health, Boston, USA
}

\begin{abstract}
Objective: To assess the epidemiological evidence on diet and cancer and make public health recommendations.

Design: Review of published studies, concentrating on recent systematic reviews, meta-analyses and large prospective studies.

Conclusions and recommendations: Overweight/obesity increases the risk for cancers of the oesophagus (adenocarcinoma), colorectum, breast (postmenopausal), endometrium and kidney; body weight should be maintained in the body mass index range of $18.5-25 \mathrm{~kg} / \mathrm{m}^{2}$, and weight gain in adulthood avoided. Alcohol causes cancers of the oral cavity, pharynx, oesophagus and liver, and a small increase in the risk for breast cancer; if consumed, alcohol intake should not exceed 2 units/d. Aflatoxin in foods causes liver cancer, although its importance in the absence of hepatitis virus infections is not clear; exposure to aflatoxin in foods should be minimised. Chinese-style salted fish increases the risk for nasopharyngeal cancer, particularly if eaten during childhood, and should be eaten only in moderation. Fruits and vegetables probably reduce the risk for cancers of the oral cavity, oesophagus, stomach and colorectum, and diets should include at least $400 \mathrm{~g} / \mathrm{d}$ of total fruits and vegetables. Preserved meat and red meat probably increase the risk for colorectal cancer; if eaten, consumption of these foods should be moderate. Salt preserved foods and high salt intake probably increase the risk for stomach cancer; overall consumption of salt preserved foods and salt should be moderate. Very hot drinks and foods probably increase the risk for cancers of the oral cavity, pharynx and oesophagus; drinks and foods should not be consumed when they are scalding hot. Physical activity, the main determinant of energy expenditure, reduces the risk for colorectal cancer and probably reduces the risk for breast cancer; regular physical activity should be taken.
\end{abstract}

Dietary factors have been thought to account for about $30 \%$ of cancers in Western countries ${ }^{1}$, making diet second only to tobacco as a preventable cause of cancer. The contribution of diet to cancer risk in developing countries has been considered to be lower, perhaps around $20 \%{ }^{2}$. Unravelling the effects of diet on cancer risk is, therefore, of great public health importance, but research to date has uncovered few definite effects and left frustratingly large areas of uncertainty.

In this paper, we summarise our view of the current state of knowledge on diet and cancer. This paper is not a systematic review of diet and cancer. Other organisations have recently published detailed reviews of this subject, in particular the World Cancer Research Fund/American Institute for Cancer Research ${ }^{3}$, and the Department of Health in the $\mathrm{UK}^{4}$. These publications provide good reviews of research published up until the mid 1990s; we have, therefore, based our review on the material summarised in these reports and on more recent studies, giving particular credence to the results of large prospective studies and to the few results from randomised controlled trials. We start by briefly discussing the types of evidence available for formulating and testing hypotheses.

\section{International comparisons, migrants and time trends}

Many of the prominent hypotheses for effects of diet on cancer risk have been derived from examination of the associations between dietary patterns and cancer rates in different populations around the world. It was noted in the 1970 s that developed Western countries have diets high in animal products, fat and sugar, and high rates of cancers of the colorectum, breast and prostate. In contrast, 
developing countries typically have diets based on one or two starchy staple foods, low intakes of animal products, fat and sugar, low rates of these 'Western' cancers, and sometimes high rates of other types of cancer such as cancers of the oesophagus, stomach and liver ${ }^{5}$. Other studies have shown that cancer rates often change in populations which migrate from one country to another, and change over time within countries. For example, the formerly low rates of colorectal cancer among Japanese people have increased both on migration to the USA and, more recently, with the increasing Westernisation of the diet in Japan ${ }^{6}$. As discussed below, some of the main hypotheses that were derived from these ecological observations have not been supported by the results of detailed studies of the diets of individuals. However, the international variations in diet and cancer rates continue to suggest that diet is an important risk factor for many common cancers, and therefore that cancer may be partly preventable by dietary changes.

Figure 1 shows estimated incidence rates for the most common cancers world-wide in $2000^{7}$. Lung cancer is the most common cancer in the world, and the most common cancer among men in both developed and developing countries, whereas breast cancer is the most common cancer among women. The archetypal Western cancers are those of the colorectum, breast and prostate. Westernisation encompasses many changes in diet and lifestyle, including increased consumption of meat, dairy
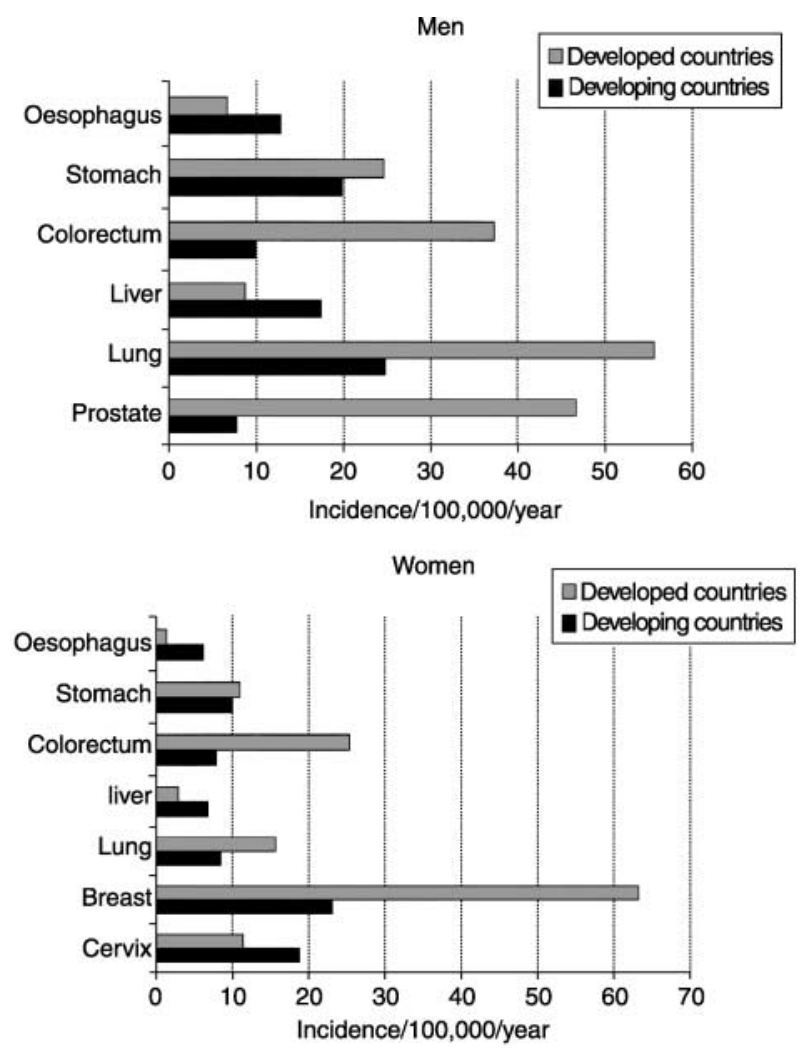

Fig. 1 Age-adjusted incidence rates of common cancers among men and women in developed and developing countries products, sugar and other refined carbohydrates, and reduced intake of relatively unrefined starchy staple foods. In terms of nutrients, Western diets are characterised by adequate or excessive energy intake, together with high intakes of protein and fat, whereas micronutrient deficiency (i.e. deficiency of vitamins or trace minerals) is much more common in developing countries. Thus, the search for the nutritional causes of the typical Western cancers has focussed mainly on excess consumption of macronutrients, whereas the search for the nutritional causes of the typical cancers of developing countries has focussed on deficient intake of micronutrients.

\section{Case-control studies}

During the last 30 years, hundreds of studies have been published that have examined the association between the diets of individuals and their risk for developing cancer. Most of the earlier studies used a case-control design, in which people who already have cancer are asked what they used to eat before they were diagnosed with cancer, and their diets are compared with those reported by people without cancer (controls). These case-control studies are useful for searching for possible dietary effects, but cannot be relied on to establish moderate dietary associations because they are susceptible to both recall and selection biases: people with cancer may recall their diet differently from healthy people, and healthy controls are rarely fully representative of the base population and may report a relatively 'healthy' diet ${ }^{8,9}$. The impact of these biases varies between studies, especially in relation to the participation rate among eligible controls, but in general relative risks in case-control studies of up to at least 1.3 may reflect bias rather than a true association.

\section{Prospective studies}

In prospective studies, dietary intakes are measured at recruitment and people are followed-up for cancer incidence, then the cancer incidence rates are compared between groups with different diets at baseline. This design eliminates the recall and selection biases to which case-control studies are susceptible, but other factors such as measurement error and confounding must be considered when interpreting the results of prospective studies (as well as case-control studies) of diet and cancer. Another limitation of most prospective studies is that the baseline dietary intake is measured at one point during adult life, which may not be the most relevant period in relation to the development of cancer over many years.

\section{Interpretation of observational studies}

Large prospective studies can establish whether or not there is any association between reported diet and cancer risk within the population studied. The main factors that need to be considered when interpreting results from such studies are measurement error and confounding. 


\section{Measurement error}

Epidemiological studies generally use a relatively short and simple dietary questionnaire. The validity of such questionnaires has been extensively investigated, and while it is clear that current assessment methods are moderately precise and can detect some associations of diet with disease risk, it is also possible that the measurement error is sometimes large enough to obscure some potentially important associations of diet with cancer risk. A further problem is that there are often strong correlations between different foods and nutrients, making it hard to attribute associations with risk to particular dietary factors, especially when the precision of the measurements is variable.

Body mass index (the weight in kilograms divided by the square of the height in metres: $\mathrm{kg} / \mathrm{m}^{2}$ ) and alcohol present special cases. Body mass index is not diet per se, but is determined by the balance of energy intake and energy expenditure; body mass index therefore serves as an indicator of chronic energy balance, and can be measured much more accurately and precisely in epidemiological studies than either energy intake or energy expenditure. Alcohol is not always included under the term diet, but alcoholic drinks do contribute a significant supply of energy and some nutrients in many populations. Although estimates of alcohol intake commonly suffer from underreporting, they generally rank individuals much more precisely than estimates of intakes of other foods and nutrients.

\section{Confounding}

Observed associations of dietary factors with cancer risk can be confounded by other risk factors for cancer, such as smoking and physical activity, which are associated with dietary habits. In theory, confounding can be allowed for by statistical adjustments, but in practice this adjustment is never perfect because the non-dietary risk factors themselves are measured with some error. The possibility that apparent dietary associations with cancer risk are confounded by other risk factors, therefore, needs to be examined very carefully. Allowing for confounding is extremely important for cancers such as lung cancer, where smoking causes a very large increase in risk and is known to be associated with diet. The relationship between diet and other cancers needs to take into account potential confounding factors, such as Helicobacter pylori for stomach cancer, physical activity for colorectal cancer, and human papillomavirus for cervical cancer (see below).

\section{Randomised controlled trials}

Randomised controlled trials eliminate both the biases and the confounding which can affect observational studies and the results can, therefore, be confidently interpreted in terms of cause and effect. Within the field of diet and cancer, however, trials are limited by the difficulty of randomising at the level of foods, and by the constraints that only a small number of nutritional factors can be tested in each trial, usually for a short period. The results of the few large trials that have been completed are important, but where trials do not show an effect it remains possible that an effect would have been seen at a different dose, at a different time in life, or if the duration of the trial had been longer. Another point which should be considered when interpreting the results from randomised controlled trials is the possibility that the effect of a dietary component on cancer risk may differ according to the characteristics of the population studied; for example, the effects of a multinutrient supplement could be more marked in a population with a low dietary intake of micronutrients than in a population with a high dietary intake of micronutrients.

Within the field of diet and cancer, randomised controlled trials are most suitable for testing hypotheses for protective effects of specific micronutrients. An extensive review of these hypotheses and of the design and interpretation of such trials is given in the first IARC Handbook of Cancer Prevention ${ }^{10}$.

\section{Review of the role of diet in the aetiology of the major cancers}

\section{Cancers of the oral cavity, pharynx and oesophagus}

Cancers of the oral cavity, pharynx and oesophagus were estimated to account for 867,000 cases and 582,000 deaths in $2000^{11}$. Incidence rates of these cancers vary widely between populations; for example, oesophageal cancer is over a hundred times more common in parts of Central Asia, China and Southern Africa than in most parts of Europe, North America and West Africa ${ }^{7}$. In developed countries, the main risk factors are alcohol and tobacco, and up to $75 \%$ of these cancers are attributable to these two lifestyle factors ${ }^{6}$. The mechanism of the effect of alcohol on these cancers is not known, but may involve direct effects on the epithelium ${ }^{12}$. Overweight/obesity is an established risk factor specifically for adenocarcinoma (but not squamous cell carcinoma) of the oesophagus ${ }^{13-}$ 15 . In developing countries, around $60 \%$ of cancers of the oral cavity, pharynx and oesophagus are thought to be due to micronutrient deficiencies related to a restricted diet that is low in fruits and vegetables and animal products $^{3,16}$; it should be noted, however, that the evidence for a protective effect of fruits and vegetables is largely derived from case-control studies and there are few data yet from prospective studies ${ }^{17}$. The relative roles of various micronutrients are not yet clear, but deficiencies of riboflavin, folate, vitamin $\mathrm{C}$ and zinc may all be important ${ }^{3,16}$. There is also consistent evidence that consuming drinks and foods at a very high temperature increases the risk for these cancers ${ }^{18}$. The results of trials in Linxian, China, aimed at reducing oesophageal cancer 
rates with micronutrient supplements, have been promising but not definitive ${ }^{19,20}$.

\section{Nasopharyngeal cancer}

This is particularly common in Southeast $\mathrm{Asia}^{7}$, and has been consistently associated with a high intake of Chinesestyle salted fish, especially during early childhood ${ }^{21,22}$, as well as with infection with the Epstein-Barr virus ${ }^{23}$. Chinese-style salted fish is a special product which is usually softened by partial decomposition before or during salting; other types of salted fish have been studied and not found to be convincingly associated with the risk for developing nasopharyngeal cancer ${ }^{22}$.

\section{Stomach cancer}

Stomach cancer was estimated to account for 876,000 cases and 647,000 deaths in $2000^{11}$. Until about 20 years ago stomach cancer was the most common cancer in the world, but mortality rates have been falling in all Western countries $^{24}$ and stomach cancer is now much more common in Asia than in Europe or North America ${ }^{7}$. Infection with the bacterium H. pylori is an established risk factor, but not a sufficient cause, for the development of stomach cancer ${ }^{25}$. Diet is also thought to be important in the aetiology of this disease, and dietary changes are implicated in the recent decline in stomach cancer incidence and mortality rates in many countries. Substantial evidence, mainly from case-control studies, suggests that risk is increased by high intakes of some traditionally preserved salted foods, especially meats and pickles, and with salt per se, and that risk is decreased by high intakes of fruits and vegetables ${ }^{26}$, perhaps due to their vitamin $\mathrm{C}$ content. However, evidence from prospective studies does not clearly support a protective effect for fruits and vegetables ${ }^{27,28}$. The introduction of refrigeration has also been associated with decreased risk, probably through reducing intakes of salted foods and facilitating year-round fruit and vegetable availability ${ }^{3}$.

The results of micronutrient supplementation trials in developing countries have been encouraging but not definitive. In Linxian, China, combined supplementation with $\beta$-carotene, selenium and $\alpha$-tocopherol resulted in a significant reduction in stomach cancer mortality, but no significant benefit was obtained from vitamin $\mathrm{C}^{19}$. A recent trial in Colombia showed increased regression of precancerous gastric dysplasia both in subjects given $\beta$-carotene and in subjects given vitamin $\mathrm{C}^{29}$.

Further prospective data are needed, in particular to examine whether some of the dietary associations may be partly confounded by $H$. pylori infection and whether dietary factors may modify the association of $H$. pylori with risk.

\section{Colorectal cancer}

Colorectal cancer is the third most common cancer in the world ${ }^{7}$ and was estimated to account for 945,000 cases and
492,000 deaths in $2000^{11}$. Incidence rates are approximately 10 -fold higher in developed than in developing countries ${ }^{7}$. It has been suggested that diet-related factors may account for up to $80 \%$ of the between-country differences in rates ${ }^{30}$. The best established dietary-related risk factor is overweight/obesity ${ }^{15}$. Alcohol probably causes a small increase in risk ${ }^{3}$. Adult height, which is partly determined by the adequacy of nutrition in childhood and adolescence, is weakly associated with increased risk, and physical activity has been consistently associated with a reduced risk ${ }^{15,31}$. These factors together, however, do not explain the large variation between populations, and there is almost universal agreement that some aspects of a Western diet are a major determinant of risk.

\section{Meat}

International correlation studies show a strong association between per capita consumption of meat and colorectal cancer mortality ${ }^{5}$, and several mechanisms have been proposed through which meat may increase cancer risk. Mutagenic heterocyclic amines and polycyclic aromatic hydrocarbons can be formed during the cooking of meat at high temperatures ${ }^{32,33}$, and nitrites and their related compounds found in smoked, salted and some processed meat products may be converted to carcinogenic $N$-nitroso compounds in the colon ${ }^{34}$. In addition, high iron levels in the colon may increase the formation of mutagenic free radicals ${ }^{35}$. The results of observational studies of meat and colorectal cancer have varied ${ }^{3}$; a recent systematic review concluded that preserved meat is associated with an increased risk for colorectal cancer but that fresh meat is not $^{36}$ and most studies have not observed positive associations with poultry or fish ${ }^{3}$. However, mortality rates for colorectal cancer are similar in Western vegetarians and comparable non-vegetarians ${ }^{37}$. Overall, the evidence is not conclusive but suggests that high consumption of preserved and red meat probably increases the risk for colorectal cancer.

\section{Fat}

As with meat, international correlation studies show a strong association between per capita consumption of fat and colorectal cancer mortality ${ }^{5}$. Possible mechanisms proposed to explain such an association are that a high fat intake may increase the levels of cytotoxic free fatty acids or secondary bile acids in the lumen of the large intestine. However, the results of observational studies of fat and colorectal cancer have, overall, not been supportive of an association with fat intake, especially after adjusting for total energy intake $\mathrm{e}^{3,38}$.

\section{Fruits, vegetables and fibre}

Burkitt $^{39}$ suggested that the low rates of colorectal cancer in Africa were due to the high consumption of dietary fibre, and there are several plausible mechanisms for a protective effect. Fibre increases stool bulk and speeds the 
transit of food through the colon, thus diluting the gut contents and perhaps reducing the absorption of carcinogens by the colonic mucosa ${ }^{40}$. Fermentation of fibre (and resistant starch) in the large intestine produces short chain fatty acids such as butyrate, which may protect against colorectal cancer through the ability to promote differentiation, induce apoptosis and/or inhibit the production of secondary bile acids by reducing luminal $\mathrm{pH}^{41,42}$. Many case-control studies of colorectal cancer have observed moderately lower risk in association with high consumption of dietary fibre, and/or fruits and vegetables ${ }^{43,44}$, but the results of recent large prospective studies have been inconsistent ${ }^{45-47}$. Furthermore, results from randomised controlled trials have not shown that intervention over a 3-4 year period with supplemental fibre or a diet low in fat and high in fibre and fruits and vegetables can reduce the recurrence of colorectal adenomas ${ }^{48-50}$. It is possible that some of the inconsistencies are due to differences between studies in the types of fibre eaten and in the methods for classifying fibre in food tables. Other possibilities are that the association with fruits and vegetables is principally due to an increase in risk at very low levels of consumption ${ }^{51}$, or that high intakes of refined flour or sugar (rather than low intakes of fibre) increase risk through chronic hyperinsulinaemia or other mechanisms ${ }^{52,53}$. At present, the hypothesis that fruits, vegetables and fibre may reduce the risk for colorectal cancer has not been firmly established.

\section{Folate}

Some recent prospective studies have suggested that a methyl-deplete diet (i.e. a diet low in folate and methionine and high in alcohol) is associated with an increased risk of colon cancer ${ }^{54,55}$. Also, use of folic acidcontaining multiple vitamin supplements has been associated with lower risk of colon cancer ${ }^{56}$. A diminished folate status may contribute to carcinogenesis by alteration of gene expression and increased DNA damage ${ }^{57,58}$ and chromosome breakage ${ }^{59}$. The finding that a common polymorphism in the methylenetetrahydrofolate reductase gene involved in folic acid metabolism may also be associated with colorectal cancer $^{60}$ strengthens the hypothesis that dietary folate may be an important factor in colorectal carcinogenesis.

\section{Calcium}

Another promising hypothesis is that relatively high intakes of calcium may reduce the risk for colorectal cancer, perhaps by forming complexes with secondary bile acids in the intestinal lumen ${ }^{3}$ or by inhibiting the hyperproliferative effects of dietary haem ${ }^{61}$. Several observational studies have supported this hypothesis ${ }^{3,4}$, and two trials have suggested that supplemental calcium may have a modest protective effect on the recurrence of colorectal adenomas ${ }^{50,62}$. More data are needed to evaluate this hypothesis.

\section{Cancer of the liver}

Liver cancer was estimated to account for 564,000 cases and 549,000 deaths in $2000^{11}$. Approximately $75 \%$ of cases of liver cancer occur in developing countries, and liver cancer rates vary over 20-fold between countries, being much higher in sub-Saharan Africa and Southeast Asia than in Europe and North America ${ }^{7}$. The major risk factor for hepatocellular carcinoma, the main type of liver cancer, is chronic infection with hepatitis $\mathrm{B}$, and to a lesser extent, hepatitis $C$ virus ${ }^{63}$. Ingestion of foods contaminated with the mycotoxin aflatoxin ${ }^{22,64}$ is an important risk factor among people in developing countries with active hepatitis virus infection. Excessive alcohol consumption is the main diet-related risk factor for liver cancer in Western countries, probably via the development of cirrhosis and alcoholic hepatitis ${ }^{6}$. Little is known about possible nutritional cofactors for viral carcinogenesis, but this may be an important area for research ${ }^{3}$.

\section{Cancer of the pancreas}

Cancer of the pancreas was estimated to account for 216,000 cases and 214,000 deaths in 2000 and is more common in Western countries than in developing countries $^{7,11}$. Time trends suggest that both incidence and mortality for cancer of the pancreas are increasing in most parts of the world, although some of this apparent increase may be due to improvements in diagnostic methods ${ }^{6}$. Overweight/obesity possibly increases the risk $^{3,65}$. Some studies have suggested that risk is increased by high intakes of meat, and reduced by high intakes of vegetables, but these data are not consistent and come mostly from case-control studies ${ }^{3}$. Over the next few years there will be substantially more prospective data on diet and cancer of the pancreas, and it is possible that more clear-cut associations with dietary factors will emerge.

\section{Lung cancer}

Lung cancer is the most common cancer in the world ${ }^{7}$ and was estimated to account for 1,239,000 cases and 1,103,000 deaths in $2000^{11}$. Heavy smoking increases the risk by around 30-fold, and smoking causes over $80 \%$ of lung cancers in Western countries ${ }^{6}$. The possibility that diet might also have an effect on lung cancer risk was raised in the 1970s following the observation that, after allowing for smoking, increased lung cancer risk was associated with a low dietary intake of vitamin $\mathrm{A}^{66}$. Since then, numerous observational studies have found that lung cancer patients generally report a lower intake of fruits, vegetables and related nutrients (such as $\beta$-carotene) than controls ${ }^{3,4}$. The only one of these factors to have been tested in controlled trials, namely $\beta$-carotene, has however, failed to produce any benefit when given as a supplement for up to 12 years ${ }^{67-69}$.

The possible effect of diet on lung cancer risk remains controversial. Several recent observational studies have continued to observe an association of fruits and 
vegetables with reduced risk, but this association has been weak in prospective studies ${ }^{70,71}$. This apparent relationship may be partly due to residual confounding by smoking, since smokers generally consume less fruits and vegetables than non-smokers, but there may also be some protective effect of these foods. In public health terms, however, the overriding priority is to reduce the prevalence of smoking.

\section{Breast cancer}

Breast cancer is the second most common cancer in the world and the most common cancer among women. Breast cancer was estimated to account for 1,105,000 cases and 373,000 deaths in women in $2000^{11}$. Incidence rates are about five times higher in Western countries than in less developed countries and Japan ${ }^{7}$. Much of this international variation is due to differences in established reproductive risk factors such as age at menarche, parity and age at births, and breastfeeding ${ }^{72,73}$, but differences in dietary habits and physical activity may also contribute. In fact, age at menarche is partly determined by dietary factors, in that restricted dietary intake during childhood and adolescence leads to delayed menarche. Adult height, also, is weakly positively associated with risk, and is partly determined by dietary factors during childhood and adolescence $^{72}$. Oestradiol and perhaps other hormones play a key role in the aetiology of breast cancer ${ }^{72}$, and it is possible that any further dietary effects on risk are mediated by hormonal mechanisms.

\section{Overweight/obesity}

Obesity increases breast cancer risk in postmenopausal women by around $50 \%$, probably by increasing serum concentrations of free oestradiol ${ }^{72}$. Obesity does not increase risk among premenopausal women (perhaps because it frequently leads to anovular menstrual cycles), but obesity in premenopausal women is likely to lead to obesity throughout life and therefore to an eventual increase in breast cancer risk.

\section{Alcohol}

The only other established dietary risk factor for breast cancer is alcohol. There is now a large amount of data from well-designed studies which consistently shows a small increase in risk with increasing consumption, with about a $7 \%$ increase in risk for an average of one alcoholic drink every day ${ }^{74}$. The mechanism for this association is not known, but may involve increases in oestrogen levels ${ }^{75}$; alternatively, some recent studies suggest that the adverse effect of alcohol may be exacerbated by a low folate intake $\mathrm{e}^{76}$

\section{Fat}

Much research and controversy has surrounded the hypothesis that a high fat intake increases breast cancer risk. The best data currently available, however, do not support this hypothesis ${ }^{77}$, and only limited data are available to evaluate whether dietary fat alters circulating oestrogen levels ${ }^{78,79}$.

\section{Other dietary factors}

The results of studies of other dietary factors including meat, dairy products, fruits and vegetables, fibre and phyto-oestrogens are inconsistent ${ }^{3,4,80,81}$.

\section{Cancer of the endometrium}

Endometrial cancer was estimated to account for 189,000 cases and 45,000 deaths in women in 2000, with the highest incidence rates occurring in Western countries ${ }^{7,11}$. Endometrial cancer risk is about 3-fold higher in obese women than lean women ${ }^{15,82}$. As with breast cancer, the effect of obesity in postmenopausal women on the risk for endometrial cancer is probably mediated by the increase in serum concentrations of oestradiol and the reduction in serum concentrations of sex hormone-binding globulin; in premenopausal women, the mechanism probably involves the increase in anovulation and consequent increased exposure to oestradiol unopposed by progesterone $^{83}$. Some case-control studies have suggested that diets high in fruits and vegetables may reduce risk and that diets high in saturated or total fat may increase risk, but the data are limited ${ }^{3}$.

\section{Cancer of the cervix}

Cancer of the cervix was estimated to account for 471,000 cases and 233,00 deaths in women in $2000^{11}$. The highest rates are in sub-Saharan Africa, Central and South America, and south-east Asia ${ }^{7}$. The major cause of cervical cancer is infection with certain subtypes of the human papillomavirus $^{84}$. Fruits, vegetables and related nutrients such as carotenoids and folate tend to be inversely related with risk $^{3,4}$, but these associations may be largely due to confounding by papillomavirus infections, smoking and other factors. Further research is needed, particularly on the possible role of folate deficiency ${ }^{3,4}$.

\section{Cancer of the ovary}

Cancer of the ovary was estimated to account for 192,000 cases and 114,000 deaths in women in $2000^{11}$, with the highest incidence rates occurring in Western countries ${ }^{7}$. Risk is reduced by high parity and by long-term use of combined oral contraceptives ${ }^{85}$. Some studies have suggested that risk is increased by high intakes of fat or dairy products, and reduced by high intakes of vegetables, but the data are not consistent and more prospective data are required to examine these possible associations ${ }^{3}$.

\section{Prostate cancer}

Prostate cancer was estimated to account for 543,000 cases and 204,000 deaths in $2000^{11}$. Prostate cancer incidence rates are strongly affected by diagnostic practices and, therefore, difficult to interpret, but mortality 
rates show that death from prostate cancer is about ten times more common in North America and Europe than in Asia $^{7}$.

Little is known about the aetiology of prostate cancer, although ecological studies suggest that it is positively associated with a Western-style diet ${ }^{5}$. The data from prospective studies have not established causal or protective associations for specific nutrients or dietary factors $^{3,4}$. Diets high in red meat, dairy products and animal fat have frequently been implicated in the development of prostate cancer, although the data are not entirely consistent ${ }^{3,86-88}$. Randomised controlled trials have provided substantial, consistent evidence that supplements of $\beta$-carotene do not alter the risk for prostate cancer ${ }^{67,68,89}$ but have suggested that vitamin $\mathrm{E}^{89}$ and selenium ${ }^{90}$ might have a protective effect. Lycopene, primarily from tomatoes, has been associated with a reduced risk in some observational studies, but the data are not consistent ${ }^{91}$

Hormones control the growth of the prostate, and interventions that lower androgen levels are moderately effective in treating this disease. Prospective studies which have examined the possible associations between serum hormone concentrations and prostate cancer risk have suggested that risk may be increased by high levels of bioavailable androgens ${ }^{92,93}$ and of insulin-like growth factor-I (IGF-I) ${ }^{94,95}$, although there are not sufficient data to consider either of these associations as established. Diet might affect prostate cancer risk by affecting hormone levels, and recent data suggest that animal protein may increase levels of IGF-I ${ }^{96,97}$.

\section{Bladder cancer}

Cancer of the urinary bladder was estimated to account for 336,000 cases and 132,000 deaths in $2000^{11}$. The geographic variation in incidence is about 10-fold, with relatively high rates in Western countries ${ }^{7}$. Smoking increases the risk for bladder cancer ${ }^{6}$. Studies suggest that high intakes of fruits and vegetables may reduce risk, but this is not established and more prospective data are needed $^{3,98,99}$

\section{Kidney cancer}

Cancer of the kidney was estimated to account for 189,000 cases and 91,000 deaths in $2000^{11}$. The range of geographic variation in incidence is moderate, with the highest incidence in Scandinavia and among the Inuit ${ }^{6}$. Overweight/obesity is an established risk factor for cancer of the kidney, and may account for up to 30\% of kidney cancers in both men and women ${ }^{100}$. There are only limited data on the possible role of diet in the aetiology of kidney cancer, but some studies have observed an increase in risk with high intakes of meat and dairy products and a reduced risk with high intakes of vegetables ${ }^{3}$.

\section{Conclusions on the effects of diet on cancer risk}

\section{Strengths and weaknesses of the evidence}

Attaining definitive evidence to confirm or refute effects of specific dietary factors on risks of human cancers is challenging and for many relationships may be impossible ${ }^{9}$. Ideally, each potential relationship would be tested in multiple randomised trials to achieve a clear conclusion. However, this is not feasible for many reasons, including the large number of dietary constituents that could be tested and the many different human cancers. In addition, uncertainty about the time in life and number of years before diagnosis that a specific aspect of diet may act hinders the design and interpretation of randomised trials. Practical problems with compliance in long-term studies and the need for many thousands of subjects create further obstacles. Finally, many dietary factors may not act in isolation and it may be their interaction with other dietary, lifestyle and/or genetic factors that may alter cell growth and affect cancer risk. For these and other reasons, randomised trials have contributed only modestly to present knowledge about diet and cancer, and this is likely to continue to be true for many years to come.

The primary alternative to randomised trials is observational studies of human cancers or their precursors, interpreted in the light of other evidence including metabolic studies, animal experiments and mechanistic investigations. Studies comparing rates of cancer in various populations and among migrants have been of prime importance in documenting the major role of environmental factors in the aetiology of nearly all major human cancers. However, from the beginning, epidemiologists have recognised that firm conclusions about specific aetiological factors cannot be based on comparisons of cancer rates among countries due to potential confounding by the multitude of lifestyle and other environmental factors that vary geographically. Case-control and prospective cohort studies within countries can provide better control of potential confounding variables, because these factors usually vary less within a geographic region and they can be measured and controlled for in statistical analyses. Until the last few years, case-control studies provided the large majority of data on diet and cancer. Concerns have existed that methodological biases, related to both the selection of study participants and the recall of diet after the diagnosis of cancer, could in some circumstances seriously distort the results of case-control studies. Now that a number of prospective studies are providing data on diet and cancer incidence, these concerns about the potential for bias in case-control studies have been supported because different results have often been observed, even within the same study population $^{8,9}$. At the time of the $1997 \mathrm{WCRF} / \mathrm{AICR}$ review $^{3}$ it was recognised that associations between dietary fat and risk of breast cancer seen in case-control studies had not been confirmed in prospective studies with substantial 
statistical power. Similar differences in results have now been observed for fat intake in relation to incidence of colon and lung cancers. A major conclusion of the 1997 review was that a greater intake of fruits and vegetables would substantially reduce risks of a broad range of cancers and decrease total cancer incidence by approximately $20 \%$. However, most of the evidence was derived from case-control studies and, again, prospective studies have often found no or only weak support for the earlier findings. In particular, prospective studies have not supported earlier suggestions for strong inverse associations between overall intakes of fruits and vegetables and risks of lung and colon cancer, and little relation has been observed with breast cancer. Because rates of oral and oesophageal cancer are low in affluent populations, these have not been adequately evaluated in prospective studies. Thus, conclusions regarding protective effects of fruits and vegetables for these cancer sites should be viewed with some caution until confirmed in prospective studies.

Although prospective cohort studies will often provide the best available evidence regarding diet and cancer relationships, like any study they also have potential limitations that should be considered in the interpretation of findings. As in almost all dietary studies, only a part of the range of possible human intakes can be investigated. Thus, conclusions need to be limited to the range of diets investigated, in part because dose-response relationships may be non-linear. As with randomised trials, conclusions about findings need to be limited to the period in life or interval between dietary assessment and cancer diagnosis that was studied. Adequate precision in measurement of dietary intakes is necessary to detect true associations; the extensive literature on validity of dietary questionnaires, and the ability of current dietary assessment methods to predict cardiovascular disease incidence, strongly suggest that major associations between dietary factors and cancer risk can be detected. In addition, prospective studies offer the opportunity for repeated measurements of dietary intake, which can reduce the error in measurement of long-term diet. However, because dietary assessments are inevitably imperfect and the size of study populations is finite, modest but still potentially important associations are usually impossible to exclude entirely. For some specific dietary factors, biochemical measurements can improve assessments of intake, but for many aspects of diet such measurements do not exist or enhance precision. A fundamental challenge in nutritional epidemiology is that foods are complex combinations of thousands of chemical constituents, thus isolation of the active factors can be difficult or impossible. For this reason, conclusions will be most reliable for foods or food groups, although data on supplement use can assist in evaluating hypotheses related to specific nutrients. Because dietary behaviours are often associated with other aspects of lifestyle that could affect cancer risk, studies also need to be evaluated for the degree to which confounding by such variables has been addressed.

Because all forms of studies have constraints, in most situations no single form of evidence will provide definitive conclusions regarding diet and cancer relationships. Thus, the best conclusions will be based on careful and critical evaluation of all forms of evidence.

\section{Summary of the evidence for dietary factors and buman cancer}

Dietary components that we believe to be convincingly or probably related to the incidence of specific cancers are summarised in Table 1, together with other dietary factors

Table 1 Diet, nutrition and cancer: levels of evidence

\begin{tabular}{|c|c|c|}
\hline Level of evidence & Decrease risk & Increase risk \\
\hline Convincing & Physical activity (colon) & $\begin{array}{l}\text { Overweight and obesity (oesophagus, colorectum, } \\
\text { breast in postmenopausal women, endometrium, } \\
\text { kidney) } \\
\text { Alcohol (oral cavity, pharynx, larynx, } \\
\text { oesophagus, liver, breast) } \\
\text { Aflatoxin (liver) } \\
\text { Chinese-style salted fish (nasopharynx) }\end{array}$ \\
\hline Probable & $\begin{array}{l}\text { Fruits and vegetables (oral cavity, } \\
\text { oesophagus, stomach, colorectum*) } \\
\text { Physical activity (breast) }\end{array}$ & $\begin{array}{l}\text { Preserved meat and red meat } \\
\text { (colorectum) } \\
\text { Salt preserved foods and salt } \\
\text { (stomach) } \\
\text { Very hot (thermally) drinks and } \\
\text { food (oral cavity, pharynx, oesophagus) }\end{array}$ \\
\hline Insufficient & $\begin{array}{l}\text { Fibre, soya, fish, } n-3 \text { fatty acids, carotenoids, vitamins } \\
B_{2}, B_{6} \text {, folate, } B_{12}, C, D, E \text {, calcium, } \\
\text { zinc, selenium, non-nutrient plant constituents } \\
\text { (e.g. allium compounds, flavonoids, isoflavones, } \\
\text { lignans) }\end{array}$ & $\begin{array}{l}\text { Animal fats, heterocyclic amines, polycyclic } \\
\text { aromatic hydrocarbons, nitrosamines }\end{array}$ \\
\hline
\end{tabular}

\footnotetext{
${ }^{*}$ A protective effect of fruit and vegetable intake has been suggested by many case-control studies but has not been supported in several large prospective
} studies, suggesting that if a benefit does exist it is likely to be modest. 
which were considered to be possibly related to cancer risk but for which the evidence was considered insufficient. Physical activity is also listed in Table 1 because it is related to energy balance and overweight/obesity; a full discussion of the effects of physical activity on cancer risk is outside the scope of this paper, therefore, we have based our evaluation on the conclusions in the IARC Handbook on Weight Control and Physical Activity $^{101}$.

\section{Dietary factors which convincingly increase risk}

\section{Overweight/obesity}

The nutritional factor for which the evidence was considered most convincing, and for which the quantitative impact on overall cancer rates is most important in populations with Western cancer incidence patterns, is overweight/obesity. Overweight/obesity is convincingly related to risks for cancers of the oesophagus (adenocarcinoma), colorectum, breast (postmenopausal), endometrium and kidney. Importantly, excess risk of these cancers increases continuously with greater adiposity and is not limited to clinical obesity (BMI over $30 \mathrm{~kg} / \mathrm{m}^{2}$ ). The large increases in endogenous estrogen levels caused by excess body fat among postmenopausal women probably explain the higher risks of postmenopausal breast and endometrial cancer. The mechanisms for other cancers are less clear, but it has been suggested that hyperinsulinaemia may increase the risk for colon cancer ${ }^{52,102}$. The WHO/IARC working group on weight control and physical activity estimated that in countries with high rates of cancers related to overweight, excess body weight (BMI over $25 \mathrm{~kg} / \mathrm{m}^{2}$ ) accounts for approximately 39\% of endometrial, 25\% of kidney, $11 \%$ of colon, $9 \%$ of postmenopausal breast cancer and $5 \%$ of total cancer incidence ${ }^{82,101}$. Although these percentages will be lower in populations in some developing countries where virally related cancers are more important, the rapid increase in overweight/obesity in developing countries means that cancers due to overweight/obesity will become increasingly important world-wide.

We recognise that overweight/obesity, a reflection of excessive energy intake, can result from both overconsumption of energy from food and low expenditure of energy as physical activity; the relative importance of these two factors can vary among individuals and populations. Considerable attention has been given to the possibility that the composition of the diet influences the probability of body fat accumulation and thus, indirectly, risk of cancer. Although the percentage of energy from dietary fat has been hypothesised to be an important determinant of body fat and the topic has been controversial, an important effect of dietary fat has not been supported in randomised trials lasting 1 year or more, and populations consuming low fat/high carbohydrate diets can clearly develop high rates of obesity ${ }^{103}$. Other dietary factors that may potentially influence the accumulation of body fat include high consumption of refined carbohydrate, highly energy-dense food (i.e. high energy content relative to volume or weight of food), and low fibre intake. However, evidence based on long-term studies for these effects of dietary composition is inadequate at present. Thus, at this time the appropriate emphasis for weight control appears to be limitation of excessive energy intake from any source and the adoption of adequate daily physical activity.

\section{Alcoholic beverages}

Another aspect of diet clearly related to cancer incidence is consumption of alcoholic beverages, which convincingly increases the risk of cancers of the oral cavity, pharynx, larynx, oesophagus, liver and breast (and probably colorectum). The increase in risk appears to be primarily due to alcohol per se rather than specific alcoholic beverages. Whereas most of the excess risks occurs with high alcohol consumption, a small (about 7\%) increase in risk of breast cancer has been observed with approximately one drink per day. Recent studies suggest that the excess risk of breast and colon cancer associated with alcohol consumption may be concentrated in persons with low folate intake.

\section{Aflatoxin}

Food contaminated with aflatoxin convincingly increases the risk of liver cancer. However, this contamination occurs mainly in areas where hepatitis viruses are a major cause of liver cancer, and the importance of aflatoxin in the absence of hepatitis virus infections (for example, after immunisation) is not clear.

\section{Chinese-style salted fish}

High intake of Chinese-style salted fish, predominantly consumed in some Asian populations, convincingly increases the risk of nasopharyngeal cancer.

\section{Dietary factors which probably reduce risk}

\section{Fruits and vegetables}

Overall, a high intake of fruits and vegetables probably reduces the risks of cancers of the oral cavity, oesophagus, stomach and colorectum. Previous reviews of diet and cancer, including the 1997 WCRF/AICR review, have given greater emphasis to increasing fruit and vegetable consumption for cancer prevention, and have included cancers of the larynx, lung, pancreas, breast and bladder. At that time, however, the available literature was based largely on case-control studies, and subsequent prospective studies have not supported important protective effects for cancers of the lung and breast, and have suggested that the reduction in risk for colorectal cancer may be modest. These discordant results, which add to concerns about the potential for bias in case-control studies, also suggest the need for some caution regarding 
conclusions about intake of fruits and vegetables and the risks of oral, oesophageal and stomach cancers, which have not been adequately examined in large prospective studies. Furthermore, none of the dietary studies of stomach cancer has controlled adequately for infection by H. pylori, which is a potential confounding variable.

Although support for a broad and strong protective effect of higher fruit and vegetable intake against cancer incidence has weakened with the results from recent studies, modest benefits of increasing fruit and vegetable intake have not been excluded and probably do exist. The issue of dose-response is important, and some evidence suggests that a very low intake of fruits and vegetables, e.g. less than 2 servings or $200 \mathrm{~g} / \mathrm{d}$, is related to increases in risk compared with higher intakes, but that there may be little additional benefit for intakes higher than about $400 \mathrm{~g} / \mathrm{d}^{51,81}$. Also, fruits and vegetables are extremely heterogeneous, and it is possible that only specific foods are related to risk for specific cancers. As examples, some studies have suggested that intake of tomato products, high in lycopene ${ }^{104}$, is inversely related to risk of prostate cancer and that cruciferous vegetable intake is inversely associated with bladder cancer incidence ${ }^{99}$. In these same studies, overall fruit and vegetable consumption was not associated with cancer risk. Should this be considered as general support for a protective effect of fruits and vegetables, or only for more specific relationships? Another complexity can arise when a micronutrient in the form of a supplement is shown to be related to cancer risk. This might be construed as evidence that fruits and vegetables containing this factor are protective against cancer. However, this does not necessarily follow because bioavailability of micronutrients in fruits and vegetables might be low or antagonistic factors might be present. Folate may provide such an example as there is now considerable evidence that higher intake, mainly due to use of multiple vitamins, may be related to lower risks of colorectal and breast cancers. Also, in this situation, use of supplements and fortified foods could mask a beneficial effect of fruits and vegetables if folate were an important protective component of these foods.

\section{Preserved meat and red meat}

In many studies, high intakes of preserved meat or red meat have been associated with increased risk of colorectal cancer, whereas the total fat content of the diet does not appear to be related to risk. The components of preserved and red meat that might increase colorectal cancer risk are not established; heterocyclic amines created by cooking, haeme iron, and specific fatty acids have been proposed as explanations.

\section{Salt preserved foods and salt}

High intakes of salt-preserved foods and of salt probably increases the risk of stomach cancer. Convincing evidence would require confirmation in prospective studies and evidence that this relationship was not confounded by $H$. pylori infection. Notably, stomach cancer rates in the US are now very low even though salt intake is not.

\section{Very bot drinks and foods}

Consumption of very hot drinks and foods typically consumed in some cultures probably increases risk of cancers of the oral cavity, pharynx and oesophagus.

\section{Cancers not included in table}

For cancers of the pancreas, lung, cervix and ovary, we did not consider these to be convincing or probable evidence of a dietary relationship. In earlier reviews, evidence had been considered stronger for a protective effect of fruit and vegetable consumption against lung cancer risk. However, more recent prospective studies have found weaker associations, and residual confounding by cigarette smoking remains a concern. Although a weak relation with fruit and vegetable intake is possible, avoidance of smoking is the only effective way to substantially reduce lung cancer rates.

Diets very high in starch and low in overall micronutrient intake, consumed by poor populations in many countries, have been associated with increased risks of oral and oesophageal cancers. Isolation of the specific micronutrients responsible has been elusive, but an overall improvement of these poverty-related diets is clearly warranted for health in general.

\section{Conclusions on dietary factors and cancer}

Since the 1981 Doll and Peto review on diet and cancer mortality ${ }^{1}$, about one third of cancers have generally been thought to be related to dietary factors. More recent evidence suggests that this number may be too high, but a revised quantitative estimate is beyond the scope of this review. Among the diet-related factors, overweight/obesity convincingly increases the risks of several common cancers. After tobacco, overweight/obesity appears to be the most important avoidable cause of cancer in populations with Western patterns of cancer incidence. Among non-smoking individuals in these populations, avoidance of overweight is the most important strategy for cancer prevention.

\section{Policy implications}

Public health policy with respect to nutrition and cancer should be based on the best available scientific research. In the previous section, we concluded that few dietary effects on cancer risk have been established. Avoiding overweight/obesity, limiting alcohol intake and increasing physical activity will reduce cancer risk, as will limiting consumption of Chinese-style salted fish and minimising dietary exposure to aflatoxin in populations where these dietary factors are important. Risk will probably be decreased by increasing the average intake of fruits and 
Table 2 Diet, nutrition and cancer: recommendations

\begin{tabular}{|c|c|}
\hline 1. & $\begin{array}{l}\text { Maintain } \mathrm{BMI} \text { in range of } \\
18.5-25 \mathrm{~kg} / \mathrm{m}^{2} \text {, and avoid weight gain } \\
\text { in adulthood }\end{array}$ \\
\hline 2. & Engage in regular physical activity \\
\hline 3. & $\begin{array}{l}\text { Consumption of alcoholic beverages is } \\
\text { not recommended: if consumed, do } \\
\text { not exceed } 2 \text { units/d ( } 1 \text { unit is equivalent to approximately } \\
10 \mathrm{~g} \text { of alcohol and is } \\
\text { provided by one glass of } \\
\text { beer, wine or spirits) }\end{array}$ \\
\hline 4. & $\begin{array}{l}\text { Minimise exposure to aflatoxin in } \\
\text { foods }\end{array}$ \\
\hline 5. & $\begin{array}{l}\text { Chinese-style salted fish should only } \\
\text { be eaten in moderation, especially } \\
\text { during childhood. Overall consumption of } \\
\text { salt-preserved foods and salt should } \\
\text { be moderate }\end{array}$ \\
\hline 6. & $\begin{array}{l}\text { Have a diet which includes } \\
\text { at least } 400 \mathrm{~g} / \mathrm{d} \text { of total fruit and } \\
\text { vegetables }\end{array}$ \\
\hline 7. & $\begin{array}{l}\text { Meat: those who are not } \\
\text { vegetarian are advised to moderate } \\
\text { consumption of preserved meat (e.g. } \\
\text { sausages, salami, bacon, ham etc.) } \\
\text { and red meat (e.g. beef, } \\
\text { pork, lamb). Poultry and fish } \\
\text { (except Chinese-style salted fish, see } \\
5 . \text { above) have been studied } \\
\text { and found not to be } \\
\text { associated with increased cancer risk }\end{array}$ \\
\hline 8. & $\begin{array}{l}\text { Do not consume foods or } \\
\text { drinks when they are at } \\
\text { a very hot (scalding hot) } \\
\text { temperature }\end{array}$ \\
\hline
\end{tabular}

vegetables, and by limiting intake of preserved and red meat, salt preserved foods and salt, and very hot drinks and food. Public health policy should, therefore, be focussed on these factors (Table 2). If other dietary factors are established to affect cancer risk then these can be added to existing policy frameworks, but at present the other potentially important dietary factors are not sufficiently well supported by evidence, and including them in policy would risk confusing priorities and diverting attention from the really important issues.

\section{Acknowledgements}

An earlier version of this paper was prepared as a background paper for the Joint WHO/FAO Expert Consultation on diet, nutrition and the porevention of chronic diseases (Geneva, 28 January-1 February 2002). The authors wish to thank Professor Tony McMichael, National Centre for Epidemiology and Population Health, Australia National University, Canberra, Australia, Dr Larry N.Kolonel, Cancer Research Center of Hawaii, University of Hawaii, Honolulu, USA, Dr Shaw Watanabe, Department of Nutrition and Epidemiology, Tokyo University of Agriculture, Tokyo, Japan, and Dr Shoichiro Tsugane, Epidemiology \& Biostatistics Division, National Cancer Center Research Institute, Kashiwa-City, Japan, for their thoughtful and constructive comments on the earlier manuscript. The authors are particularly thankful to Dr Elio Riboli, International Agency for Research on Cancer (IARC), Lyon, France, for his valuable help and contributions during the drafting of the manuscript.

\section{References}

1 Doll R, Peto R. The causes of cancer: quantitative estimates of avoidable risks of cancer in the United States today. Journal of the National Cancer Institute 1981; 66: 1191-308.

2 Miller AB. Diet in cancer prevention. http://www.who.int/ ncd/cancer/publications/abstracts/abs9810_05 (accessed 2001).

3 World Cancer Research Fund. Food, Nutrition, and the Prevention of Cancer: A Global Perspective. Washington, DC: American Institute for Cancer Research, 1997.

4 COMA. Nutritional Aspects of the Development of Cancer (Report of the Working Group on Diet and Cancer of the Committee on Medical Aspects of Food and Nutrition Policy). London: The Stationery Office, 1998.

5 Armstrong B, Doll R. Environmental factors and cancer incidence and mortality in different countries, with special reference to dietary practices. International Journal of Cancer 1975; 15: 617-31.

6 International Agency for Research on Cancer. Cancer: Causes, Occurrence and Control. IARC Scientific Publications No. 100. Lyon: IARC, 1990.

7 FerIay J, Bray P, Pisani P, Parkin DM. Globocan 2000: Cancer incidence, mortality and prevalence worldwide, Version 1.0. IARC CancerBase No. 5. http://www-dep.iarc. fr/globocan/globocan.html (accessed Nov 3, 2001).

8 Giovannucci E, Stampfer MJ, Colditz GA, et al. A comparison of prospective and retrospective assessments of diet in the study of breast cancer. American Journal of Epidemiology 1993; 137: 502-11.

9 Willett WC. Nutritional Epidemiology. New York: Oxford University Press, 1998.

10 International Agency for Research on Cancer. Principles of Chemoprevention. IARC Scientific Publications No. 139. Lyon: IARC, 1996.

11 Parkin DM, Bray F, Ferlay J, Pisani P. Estimating the world cancer burden: Globocan 2000. International Journal of Cancer 2001; 94: 153-6.

12 International Agency for Research on Cancer. IARC Monographs on the Evaluation of Carcinogenic Risks to Humans, vol. 44. Alcohol drinking. Lyon: IARC, 1988.

13 Brown LM, Swanson CA, Gridley G, et al. Adenocarcinoma of the esophagus: role of obesity and diet. Journal of the National Cancer Institute 1995; 87: 104-9.

14 Cheng KK, Sharp L, McKinney PA, et al. A case-control study of oesophageal adenocarcinoma in women: a preventable disease. British Journal of Cancer 2000; 83: $127-32$.

15 International Agency for Research on Cancer. Overweight and lack of exercise linked to increased cancer risk. IARC Handbooks of Cancer Prevention. vol. 6. Geneva: World Health Organisation, 2002.

16 World Health Organisation: International Agency for Research on Cancer. Cancer: Causes, Occurrence and Control. Lyon: IARC, 1990.

17 Steinmetz KA, Potter JD. Vegetables, fruit, and cancer prevention: a review. Journal of the American Dietetic Association 1996; 96: 1027-39.

18 Sharp L, Chilvers CE, Cheng KK, et al. Risk factors for squamous cell carcinoma of the oesophagus in women: a case-control study. British Journal of Cancer 2001; 85: $1667-70$. 
19 Blot WJ, Li JY, Taylor PR, et al. Nutrition intervention trials in Linxian, China: supplementation with specific vitamin/ mineral combinations, cancer incidence, and diseasespecific mortality in the general population. Journal of the National Cancer Institute 1993; 85: 1483-92.

20 Li JY, Taylor PR, Li B, et al. Nutrition intervention trials in Linxian, China: multiple vitamin/mineral supplementation, cancer incidence, and disease-specific mortality among adults with esophageal dysplasia. Journal of the National Cancer Institute 1993; 85: 1492-8.

$21 \mathrm{Yu}$ MC. Nasopharyngeal carcinoma: epidemiology and dietary factors. In: O'Neill IK, Chen J, Bartsch H, eds. Relevance to Human Cancer of N-nitroso Compounds, Tobacco Smoke and Mycotoxins. IARC Scientific Publications No. 105. Lyon: 1ARC, 1991, 39-47.

22 International Agency for Research on Cancer. IARC Monographs on the Evaluation of Carcinogenic Risks to Humans, vol 56. Some Naturally Occurring Substances: Food Items and Constituents, Heterocyclic Aromatic Amines and Mycotoxins. Lyon: IARC, 1993.

23 Doll R, Peto R. Epidemiology of cancer. In: Weatherall DJ, Ledingham JGG, Warrell DA, eds. Oxford Textbook of Medicine. Oxford: Oxford University Press, 1996, 197-221.

24 World Health Organisation. World Health Statistics Annual. http://www.who.int/whosis/ (accessed Nov 10, 2001).

25 Helicobacter and Cancer Collaborative Group. Gastric cancer and Helicobacter pylori: a combined analysis of 12 case control studies nested within prospective cohorts. Gut 2001; 49: 347-53.

26 Palli D. Epidemiology of gastric cancer: an evaluation of available evidence. Journal of Gastroenterology 2000; 35(Suppl. 12): 84-9.

27 McCullough ML, Robertson AS, Jacobs EJ, Chao A, Calle EE, Thun MJ. A prospective study of diet and stomach cancer mortality in United States men and women. Cancer Epidemiology Biomarkers \& Prevention 2001; 10: 1201-5.

28 Botterweck AA, van den Brandt PA, Goldbohm RA. A prospective cohort study on vegetable and fruit consumption and stomach cancer risk in The Netherlands. American Journal of Epidemiology 1998; 148: 842-53.

29 Correa P, Fontham ET, Bravo JC, et al. Chemoprevention of gastric dysplasia: randomized trial of antioxidant supplements and anti-Helicobacter pylori therapy. Journal of the National Cancer Institute 2000; 92: 1881-8.

30 Cummings JH, Bingham SA. Diet and the prevention of cancer. British Medical Journal 1998; 317: 1636-40.

31 Hardman AE. Physical activity and cancer risk. Proceeding of the Nutrition Society 2001; 60: 107-13.

32 Gooderham NJ, Murray S, Lynch AM, et al. Assessing human risk to heterocyclic amines. Mutation Research 1997; 376: 53-60.

33 Kazerouni N, Sinha R, Hsu CH, Greenberg A, Rothman N. Analysis of 200 food items for benzo[a]pyrene and estimation of its intake in an epidemiologic study. Food Chemistry and Toxicology 2001; 39: 423-36.

34 Bingham SA, Pignatelli B, Pollock JR, et al. Does increased endogenous formation of $N$-nitroso compounds in the human colon explain the association between red meat and colon cancer? Carcinogenesis 1996; 17: 515-23.

35 Lund EK, Wharf SG, Fairweather-Tait SJ, Johnson IT Oral ferrous sulfate supplements increase the free radical-generating capacity of feces from healthy volunteers. American Journal of Clinical Nutrition 1999; 69: $250-5$.

36 Norat T, Lukanova A, Ferrari P, Riboli E. Meat consumption and colorectal cancer risk: a dose-response meta-analysis of epidemiological studies. International Journal of Cancer 2002; 98: 241-56.

37 Key TJ, Fraser GE, Thorogood M, et al. Mortality in vegetarians and non-vegetarians: a collaborative analysis of
8300 deaths among 76,000 men and women in five prospective studies. Public Health Nutrition 1998; 1: 33-41.

38 Howe GR, Aronson KJ, Benito E, et al. The relationship between dietary fat intake and risk of colorectal cancer: evidence from the combined analysis of 13 case-control studies. Cancer Causes \& Control 1997; 8: 215-28.

39 Burkitt DP. Related disease_related cause? Lancet 1969; 2: 1229-31

40 La Vecchia C. Diet and human cancer: a review. European Journal of Cancer Prevention 2001; 10: 177-81.

41 Hague A, Elder DJ, Hicks DJ, Paraskeva C. Apoptosis in colorectal tumour cells: induction by the short chain fatty acids butyrate, propionate and acetate and by the bile salt deoxycholate. International Journal of Cancer 1995; 60 400-6.

42 Nagengast FM, Grubben MJ, van Munster IP. Role of bile acids in colorectal carcinogenesis. European Journal of Cancer 1995; 31A: $1067-70$.

43 Potter JD, Steinmetz K. Vegetables, fruit and phytoestrogens as preventive agents. In: Stewart BW, McGregor D, eds. Principles of Chemoprevention. IARC Scientific Publication No. 139. Lyon: 1ARC, 1996, 61-90.

44 Jacobs DRJ, Marquart L, Slavin J, Kushi LH. Whole-grain intake and cancer: an expanded review and meta-analysis. Nutrition and Cancer 1998; 30: 85-96.

45 Bueno De Mesquita HB, Ferrari P, Riboli E, on behalf of EPIC. Plantfoods and the risk of colorectal cancer in Europe: preliminary findings. IARC Scientific Publications Series. 2002; 156: 89-95.

46 Fuchs CS, Giovannucci EL, Colditz GA, et al. Dietary fiber and the risk of colorectal cancer and adenoma in women. New England Journal of Medicine 1999; 340: 169-76.

47 Michels KB, Edward G, Joshipura KJ, et al. Prospective study of fruit and vegetable consumption and incidence of colon and rectal cancers. Journal of the National Cancer Institute 2000; 92: 1740-52.

48 Schatzkin A, Lanza E, Corle D, et al. Lack of effect of a lowfat, high-fiber diet on the recurrence of colorectal adenomas. Polyp Prevention Trial Study Group. New England Journal of Medicine 2000; 342: 1149-55.

49 Alberts DS, Martinez ME, Roe DJ, et al. Lack of effect of a high-fiber cereal supplement on the recurrence of colorectal adenomas. Phoenix Colon Cancer Prevention Physicians' Network. New England Journal of Medicine 2000; 342: 1156-62

50 Bonithon-Kopp C, Kronborg O, Giacosa A, Rath U, Faivre J. Calcium and fibre supplementation in prevention of colorectal adenoma recurrence: a randomised intervention trial. European Cancer Prevention Organisation Study Group. Lancet 2000; 356: 1300-6.

51 Terry P, Giovannucci E, Michels KB, et al. Fruit, vegetables, dietary fiber, and risk of colorectal cancer. Journal of the National Cancer Institute 2001; 93: 525-33.

52 McKeown-Eyssen G. Epidemiology of colorectal cancer revisited: are serum triglycerides and/or plasma glucose associated with risk? Cancer Epidemiology Biomarkers $\mathcal{E}$ Prevention 1994; 3: 687-95.

53 Franceschi S, Dal Maso L, Augustin L, et al. Dietary glycemic load and colorectal cancer risk. Annals of Oncology 2001; 12: $173-8$.

54 Giovannucci E, Rimm EB, Ascherio A, Stampfer MJ, Colditz GA, Willett WC. Alcohol, low-methionine, low-folate diets, and risk of colon cancer in men. Journal of the National Cancer Institute 1995; 87: 265-73.

55 Glynn SA, Albanes D, Pietinen P, et al. Alcohol consumption and risk of colorectal cancer in a cohort of Finnish men. Cancer Causes \& Control 1996; 7: 214-23.

56 Giovannucci E, Stampfer MJ, Colditz GA, et al. Multivitamin use, folate, and colon cancer in women in the Nurses 
Health Study. Annals of Internal Medicine 1998; 129 $517-24$.

57 Choi SW, Mason JB. Folate and carcinogenesis: an integrated scheme. Journal of Nutrition 2000; 130: 129-32.

58 Potter JD. Colorectal cancer: molecules and populations. Journal of the National Cancer Institute 1999; 91: 916-32.

59 Blount BC, Mack MM, Wehr CM, et al. Folate deficiency causes uracil misincorporation into human DNA and chromosome breakage: implications for cancer and neuronal damage. Proceedings of the National Academy of Sciences of the United States of America 1997; 94: 3290-5.

60 Ma J, Stampfer MJ, Christensen B, et al. A polymorphism of the methionine synthase gene: association with plasma folate, vitamin B12, homocyst(e)ine, and colorectal cancer risk. Cancer Epidemiology Biomarkers \& Prevention 1999; 8: 825-9.

61 Sesink AL, Termont DS, Kleibeuker JH, Van Der Meer R. Red meat and colon cancer: dietary haem-induced colonic cytotoxicity and epithelial hyperproliferation are inhibited by calcium. Carcinogenesis 2001; 22: 1653-9.

62 Baron JA, Beach M, Mandel JS, et al. Calcium supplements and colorectal adenomas. Polyp Prevention Study Group. Annals of the New York Academy of Sciences 1999; 889: $138-45$.

63 International Agency for Research on Cancer. IARC Monographs on the Evaluation of Carcinogenic Risks to Humans, vol 59. Hepatitis Viruses. Lyon: IARC, 1994.

64 Saracco G. Primary liver cancer is of multifactorial origin: importance of hepatitis B virus infection and dietary aflatoxin. Journal of Gastroenterology and Hepatology 1995; 10: 604-8.

65 Michaud DS, Giovannucci E, Willett WC, Colditz GA, Stampfer MJ, Fuchs CS. Physical activity, obesity, height, and the risk of pancreatic cancer. Journal of the American Medical Association 2001; 286: 921-9.

66 Bjelke E. Dietary vitamin A and human lung cancer. International Journal of Cancer 1975; 15: 561-5.

67 Hennekens CH, Buring JE, Manson JE, et al. Lack of effect of long-term supplementation with beta carotene on the incidence of malignant neoplasms and cardiovascular disease. New England Journal of Medicine 1996; 334: $1145-9$.

68 Omenn GS, Goodman GE, Thornquist MD, et al. Effects of a combination of beta carotene and vitamin A on lung cancer and cardiovascular disease. New England Journal of Medicine 1996; 334: 1150-5

69 The Alpha-Tocopherol Beta Carotene Cancer Prevention Study Group. The effect of vitamin E and beta carotene on the incidence of lung cancer and other cancers in male smokers. New England Journal of Medicine 1994; 330: 1029-35.

70 Feskanich D, Ziegler RG, Michaud DS, et al. Prospective study of fruit and vegetable consumption and risk of lung cancer among men and women. Journal of the National Cancer Institute 2000; 92: 1812-23.

71 Voorrips LE, Goldbohm RA, Verhoeven DT, et al. Vegetable and fruit consumption and lung cancer risk in the Netherlands Cohort Study on diet and cancer. Cancer Causes \& Control 2000; 11: 101-15.

72 Key TJ, Verkasalo PK, Banks E. Epidemiology of breast cancer. Lancet Oncology 2001; 2: 133-40.

73 Collaborative Group on Hormonal Factors in Breast Cancer. Breastfeeding and breast cancer: collaborative reanalysis of individual data from 47 epidemiological studies in 30 countries, including 50,302 women with breast cancer and 96,973 women without the disease. Lancet 2002; 360 : $187-95$.

74 Collaborative group on hormonal factors in breast cancer. Alcohol, tobacco and breast cancer-collaborative reanalysis of individual data from 53 epidemiological studies, including 58,515 women with breast cancer and 95,067 women without the disease. British Journal of Cancer 2002; 87: 1234-45.

75 Dorgan JF, Baer DJ, Albert PS, et al. Serum hormones and the alcohol-breast cancer association in postmenopausal women. Journal of the National Cancer Institute 2001; 93 : $710-5$.

76 Sellers TA, Kushi LH, Cerhan JR, et al. Dietary folate intake, alcohol, and risk of breast cancer in a prospective study of postmenopausal women. Epidemiology 2001; 12: 420-8.

77 Smith-Warner SA, Spiegelman D, Adami HO, et al. Types of dietary fat and breast cancer: a pooled analysis of cohort studies. International Journal of Cancer 2001; 92 : 767-74.

78 Wu AH, Pike MC, Stram DO. Meta-analysis: dietary fat intake, serum estrogen levels, and the risk of breast cancer. Journal of the National Cancer Institute 1999; 91: 529-34.

79 Holmes MD, Spiegelman D, Willett WC, et al. Dietary fat intake and endogenous sex steroid hormone levels in postmenopausal women. Journal of Clinical Oncology 2000; 18: 3668-76.

80 Key TJ, Allen NE. Nutrition and breast cancer. The Breast 2001; 10(Suppl. 3): 9-13.

81 Smith-Warner SA, Spiegelman D, Yaun SS, et al. Intake of fruits and vegetables and risk of breast cancer: a pooled analysis of cohort studies. Journal of the American Medical Association 2001; 285: 769-76.

82 Bergstrom A, Pisani P, Tenet V, Wolk A, Adami HO. Overweight as an avoidable cause of cancer in Europe. International Journal of Cancer 2001; 91: 421-30.

83 Key TJ, Pike MC. The dose-effect relationship between 'unopposed' oestrogens and endometrial mitotic rate: its central role in explaining and predicting endometrial cancer risk. British Journal of Cancer 1988; 57: 205-12.

84 International Agency for Research on Cancer. IARC Monographs on the Evaluation of Carcinogenic Risks to Humans, vol 64. Human Papillomaviruses. Lyon: IARC, 1995.

85 Banks E, Beral V, Reeves G. The epidemiology of epithelial ovarian cancer: a review. International Journal of Gynecological Cancer 1997: 425-38.

86 Schuurman AG, van den Brandt PA, Dorant E, Goldbohm RA. Animal products, calcium and protein and prostate cancer risk in The Netherlands Cohort Study. British Journal of Cancer 1999; 80: 1107-13.

87 Chan JM, Stampfer MJ, Ma J, Gann PH, Gaziano JM, Giovannucci EL. Dairy products, calcium, and prostate cancer risk in the Physicians' Health Study. American Journal of Clinical Nutrition 2001; 74: 549-54.

88 Michaud DS, Augustsson K, Rimm EB, Stampfer MJ, Willett WC, Giovannucci E. A prospective study on intake of animal products and risk of prostate cancer. Cancer Causes E Control 2001; 12: 557-67.

89 Heinonen OP, Albanes D, Virtamo J, et al. Prostate cancer and supplementation with alpha-tocopherol and beta-carotene: incidence and mortality in a controlled trial. Journal of the National Cancer Institute 1998; 90 : $440-6$.

90 Clark LC, Dalkin B, Krongrad A, et al. Decreased incidence of prostate cancer with selenium supplementation: results of a double-blind cancer prevention trial. British Journal of Urology 1998; 81: 730-4.

91 Kristal AR, Cohen JH. Invited commentary: tomatoes, lycopene, and prostate cancer. How strong is the evidence? American Journal of Epidemiology 2000; 151: 124-7.

92 Eaton NE, Reeves GK, Appleby PN, Key TJ. Endogenous sex hormones and prostate cancer: a quantitative review of prospective studies. British Journal of Cancer 1999; 8 : $930-4$. 
93 Gann PH, Hennekens CH, Ma J, Longcope C, Stampfer MJ. Prospective study of sex hormone levels and risk of prostate cancer. Journal of the National Cancer Institute 1996; 88: 1118-26.

94 Chan JM, Stampfer MJ, Giovannucci E, et al. Plasma insulinlike growth factor-I and prostate cancer risk: a prospective study. Science 1998; 279: 563-6.

95 Stattin P, Bylund A, Rinaldi S, et al. Plasma insulin-like growth factor-I, insulin-like growth factor-binding proteins and prostate cancer risk: a prospective study. Journal of the National Cancer Institute 2000; 92: 1910-7.

96 Allen NE, Appleby PN, Davey GK, Key TJ. Hormones and diet: low insulin-like growth factor-I but normal bioavailable androgens in vegan men. British Journal of Cancer 2000; 83: 95-7.

97 Heaney RP, McCarron DA, Dawson-Hughes B, et al. Dietary changes favorably affect bone remodeling in older adults. Journal of the American Dietetic Association 1999; 99 1228-33.

98 Zeegers MP, Goldbohm RA, van den Brandt PA. Consumption of vegetables and fruits and urothelial cancer incidence: a prospective study. Cancer Epidemiology Biomarkers \& Prevention 2001; 10: 1121-8.

99 Michaud DS, Spiegelman D, Clinton SK, Rimm EB, Willett WC, Giovannucci EL. Fruit and vegetable intake and incidence of bladder cancer in a male prospective cohort. Journal of the National Cancer Institute 1999; 91 : 605-13.

100 Bergstrom A, Hsieh CC, Lindblad P, Lu CM, Cook NR, Wolk A. Obesity and renal cell cancer-a quantitative review. British Journal of Cancer 2001; 85: 984-90.

101 International Agency for Research on Cancer. IARC Handbooks of Cancer Prevention. Vol 6. Weight Control and Physical Activity. Lyon: IARC, 2002.

102 Giovannucci E. Insulin and colon cancer. Cancer Causes $\mathcal{E}$ Control 1995; 6: 164-79.

103 Willett WC. Is dietary fat a major determinant of body fat? American Journal of Clinical Nutrition 1998; 67: 556S-62S.

104 Giovannucci E, Clinton SK. Tomatoes, lycopene, and prostate cancer. Proceedings of the Society for Experimental Biology and Medicine 1998; 218: 129-39.

\section{Note added in press-acrylamide}

Acrylamide is a chemical classified by the International Agency for Research on Cancer as a probable human carcinogen ${ }^{1}$. This classification is based on experiments in rats and mice, which show that high doses of acrylamide increase the risk for several cancers, including cancers of the lung, mammary gland, thyroid and oral cavity. In 2002, a
Swedish food survey reported that common foods such as fried potatoes, potato crisps (chips), bread and breakfast cereals contain moderately high levels of acrylamide ${ }^{2}$. Subsequent studies showed that acrylamide is generated when the amino acid asparagine is heated above $100^{\circ} \mathrm{C}$ in the presence of sugars; potatoes and cereals are both rich in asparagine $^{3,4}$. Moderate acrylamide levels in common foods have now been reported from several countries, and these findings have raised concern that dietary acrylamide may increase cancer risk in humans ${ }^{5}$. The intake of acrylamide from food may be several hundred-fold lower than the lowest dose at which adverse effects have been observed in rats ${ }^{6}$, and at the time of writing (January 2003) the only information concerning cancer risk in humans comes from a case-control study in Sweden ${ }^{7}$. This study estimated acrylamide intake from the reported intake of 10 foods, and observed no evidence that increasing intake of food sources of acrylamide was associated with the risk for cancers of the colorectum, kidney or bladder. Although these first results are moderately reassuring, more data are urgently needed from studies using questionnaires validated for estimating acrylamide intake, or biomarkers of acrylamide exposure.

\section{Further reading}

1 International Agency for Research in Cancer. Acrylamide. IARC Monographs on the Evaluation of Carcinogenic Risks to Humans 1994; 60: 389-433.

2 Tarake E, Rydberg P, Karlsson P, Eriksson S, Törnqvist M. Analysis of acrylamide, a carcinogen formed in heated foodstuffs. Journal of Agricultural and Food Chemistry 2002; 50: $4998-5006$

3 Mottram DS, Wedzicha BL, Dodson AT. Food chemistry: acrylamide is formed in the Maillard reaction. Nature 2002; 419: 448-9.

4 Stadler RH, Blank I, Varga N, et al. Food chemistry: acrylamide from Maillard reaction products. Nature 2002; 419: 449-50.

5 Food and Agriculture Organization/ World Health Organization. FAO/WHO Consultation on the Health Implications or Acrylamide in Food: Summary Report. Geneva: WHO, 2002.

6 Shaw I, Thomson B. Acrylamide food risk. Lancet 2003; $36 \mathbf{1}$ 434.

7 Mucci LA, Dickman PW, Steineck G, Adami H-O, Augustsson K. Dietary acrylamide and cancer of the large bowel, kidney, and bladder: absence of an association in a population-based study in Sweden. British Journal of Cancer 2003; 88: 84-9. 